\title{
Bullying Prevention in an Elementary School: An Exploration of Educator and Staff Perspectives
}

\author{
Stephanie L. Baller (Corresponding author) \\ Department of Health Sciences, James Madison University \\ 235 Martin Luther King Jr. Way, MSC 4301, Harrisonburg, VA 22807, USA \\ Tel: 540-568-8973Ｅ-mail: ballers1@jmu.edu
}

Jeanne Z. Wenos

Department of Health Professions, James Madison University

235 Martin Luther King Jr. Way, MSC 4315 Harrisonburg, VA 22807, USA

E-mail:wenosjz@jmu.edu

\author{
Andrew A. Peachey \\ Department of Health Sciences, James Madison University \\ 235 Martin Luther King Jr. Way, MSC 4301, Harrisonburg, VA 22807, USA \\ E-mail: peacheaa@jmu.edu
}

Received: April 8, 2019 Accepted: May 20, 2019 Published: May 28, 2019

doi:10.5296/jei.v5i1.14634 URL: https://doi.org/10.5296/jei.v5i1.14634

\begin{abstract}
The implementation of school-wide anti-bullying programs has received mixed, though predominantly positive, results in the United States. The present study sought to investigate attributes of a successful anti-bullying campaign with specific interest in areas for continued improvement. The instructional faculty, content area specialists, staff employees, and administrators of a rural mid-Atlantic elementary school were solicited to participate in audio recorded interviews regarding their perceptions of the program at their school. All participants indicated the program was largely successful at their school and the recommendations for further improvements included expanding the bullying reduction training to non-teaching staff, continued emphasis on emotional skills, inclusion of
\end{abstract}


information on varying perspectives regarding gender and culture, and expanding the training to emphasize employee interactions as an important component of the anti-bullying climate.

Keywords: bullying, relational aggression, friendship, incivility

\section{Introduction}

Bullying behaviors in schools constitute a complex childhood problem that has gained global attention (Cornell \& Mayer, 2010; Fandrem, Strohmeier, \& Roland, 2009; Marsh, Nagengast, Morin, Parada, Craven, \& Hamilton, 2011; Olweus, 1994). Liu and Graves (2011) suggested that, although bullying is identified as a construct separate from aggressive behaviors, the two are associated. In fact, it is well-established that children who are outwardly aggressive, or who appear anxious or fearful in peer interactions, are likely to establish adversarial peer relationships and even remain without friends (Ladd \& Troop-Gordon, 2003). Moreover, bullying is known to be contagious within peer groups, as it is often experienced as aggression throughout middle childhood and is then amplified in adolescence to include other undesirable group behaviors, such as smoking and drug use. Contagion of behaviors is thought to stem from influential processes related to friendships and cliques (Dishion \& Tipsord, 2011).

Peachey, Wenos, and Baller (2017) found trait emotional intelligence in elementary school children, grades 3-5, was negatively associated with bullying and, in boys, victimization, and may further assist in the formation of meaningful friendships. The formation of healthy attachments and friendships is vital to human development (Ladd \& Troop-Gordon, 2003; Smart, 2012). Children learn through friendship that peers reciprocate many attributes, such as trustworthiness, helpfulness, and other positive dispositions. Children who experience close friendships may hypothesize all peers possess similar traits, while those without friends may lack understanding about the support friendships provide (Ladd \& Troop-Gordon, 2003). Mutual and stable friendships were shown to develop among young children in kindergarten upon entry into school (Fink, Begeer, Peterson, Slaughter, \& de Rosnay, 2015), while chronic friendlessness was shown to emerge between kindergarten and third grade (Ladd \& Troop-Gordon, 2003). Chronic peer rejection was shown to be indirectly linked to loneliness through a low sense of self-acceptance in a social setting upon realizing one was disliked by others, which led to internalizing an erroneous conception that one is 'unlikeable' (Ladd \& Troop-Gordon, 2003). Even when surrounded by others, children have reported feeling lonely (Galanaki, Polychronopoulou, \& Babalis, 2008), and numerous characteristics of peer functioning, such as being teased, victimized, or excluded, were linked to loneliness in childhood (Jobe-Shields, Cohen, \& Parra, 2011).

Children's early behavioral dispositions of anxiety, fear, and aggression have been directly linked to later problems of internalization and victimization (Ladd \& Troop-Gordon, 2003). School children with behavioral problems were found to experience a higher incidence of loneliness and social dissatisfaction while simultaneously adjusting poorly to academics. Children who self-reported they were lonely were also adequately identified as lonely by teachers (Galanaki, Polychronopoulou, \& Babalis, 2008). Adults' efforts to help children self-regulate emotions by monitoring and providing structure were identified as useful in 
reducing the spread of negative group behaviors (Dishion \& Tipsord, 2011).

Relational aggression, such as bullying, is described as uncivil verbal, physical, and psychological behaviors exchanged among peers in school or the workplace (Blair, 2013; Olweus, 1994). Verbal violence is characterized by rude or condescending comments or verbal attacks. Physical violence may also include sexual misconduct, and psychological violence, the most subtle of the three, includes behaviors, such as an unwillingness to collaborate, or a desire to undermine an individual's integrity and professional reputation, or the act of blaming someone else in front of another and, in general, lacking empathy (Blair, 2013). Relational aggression differs somewhat from bullying because both victim and perpetrator are equals in positional power (Blair, 2013; Kanetsuna, Smith, \& Morita, 2006; Olweus, 1994). Incivility, a term used synonymously in this paper with relational aggression, is defined as behaviors one directs towards another individual including, but not limited to, interactions that are tense, belittling or humiliating, showing condescension, and/or making accusations, withholding information, and gossiping or spreading rumors (Norris, 2010).

Bullying and relational aggression are not limited to children and adolescents. These behaviors may persist through post-secondary education and within the workplace. Faucher, Cassidy, and Jackson (2015) reported prevalence rates of 30-40\% among workplace studies in their review. The education sector may have the highest incidence of workplace bullying (O'Connell, Calvert, \& Watson, 2007). Barclay and Aquino (2011) presented models that provide explanations of the predictors and outcomes of workplace aggression. Individual and situational level predictors combine within the organizational level to lead to aggression; the aggression may lead to attitudinal, health, psychological, or behavioral outcomes. Although the literature on bullying among children is more prolific than that which describes how adults are relating to one another in schools, a growing body of literature supports the presence of bullying within the education workforce with rates between 25 and $60 \%$ (Facucher, Cassidy, \& Jackson, 2015). The publication of several noteworthy books, including Faculty Incivility (Twale \& De Luca, 2008) and Bully in the Ivory Tower (Hollis, 2012) have served foundationally for the expanding evidence of bullying as a prevalent issue within academia and as a concerning societal issue of the workplace. Wright and Hill (2015) reported that, "workplace norms of mutual respect and civility foster organizational learning climates that encourage employees to share knowledge and mutually assist one another's professional and personal development" (p. 14). Less evidence has been established about adult relational aggression and incivility among employees of elementary education. Together the relationships among adults, between teacher and students, and within student peer groups dictate the elementary school environment. However, the perceptions of how the particular combination of peer and power groups interact is not well understood.

The purpose of the current study was to describe the meaning and essence of the lived experience of elementary school personnel on bullying behaviors among children and relational aggression among adults in a school setting, and to explain the structure and complexity of relationships among adults, between teachers and students, and within student peer groups in that context. 


\subsection{Research Questions}

(1) Do teachers and staff utilize a consistent definition of bullying?

(2) What types of bullying, contexts, and antecedents are considered to be most salient?

(3) How were teachers and staff prepared to prevent or manage bullying?

(4) What were the actual experiences of teachers and staff managing instances of bullying?

(5) How did the relationships among the adults affect the children in the school?

(6) In what ways did bullying impact students in the context of the school climate?

\section{Methods}

Permission was granted by the Institutional Review Board and the Superintendent of Schools to conduct this study at a local elementary school. Permission was also granted by the building administrator to conduct interviews in a quiet location within the school building. The research team conducted a series of personal interviews $(n=15)$ to determine the perceptions of teachers and school personnel about the school environment with regards to bullying behaviors of children and the means for addressing the behaviors by the adults in the building.

\subsection{Participants}

A convenience sample was selected from a rural elementary school. Participants represented instructional faculty (grades 1-5), content area specialists (music, physical education, technology, contractual day counselor, guidance counselor, and librarian), staff employees (cafeteria worker, school nurse, bus driver), and individuals with administrative positions within the school. Each representative group of school personnel contained multiple members. For example, each grade level contained between three and four teachers from which participants were randomly selected. All personnel who were identified through this process were invited by email or in-person to participate. Consent forms were obtained from all who agreed to participate in the study $(\mathrm{n}=15)$.

\subsection{Design and Procedures}

A phenomenological approach was employed in this study. The process began by administering semi-structured interviews to the participants in the study who were school employees. All participants were interviewed by at least two of the authors in the school building, either in a conference room, unoccupied classroom, or private office. The interview questions were focused on factors related to perceptions of school climate regarding bullying among school children, such as perceived importance of bullying within the school environment, the types of bullying considered to be most common, a description of any training available to school personnel, and the ways they believed bullying impacted students in the context of the school climate.

Transcripts of each interview were read by the authors and coded by two of the authors. Data were analyzed inductively by identifying patterns and themes throughout the transcripts. This 
process of open coding was conducted early in the analytical process. Analytic triangulation occurred when insights were shared through multiple discussions of similar and different ways of seeing the same set of data.

\subsection{Instrumentation}

Interviews were digitally audio recorded and subsequently transcribed with the help of Nuance Dragon Naturally Speaking Software (version 13). In all cases, field notes were taken during the interviews and, in two cases, it was not possible to record the interviews, so the researchers relied solely upon field notes taken during the interview.

\section{Findings}

\subsection{Do Teachers and Staff Utilize a Consistent Definition of Bullying?}

It was important to inquire about the way employees defined bullying to determine if they were in agreement conceptually about how to recognize acts of bullying and victimization and to better understand the bullying intervention protocol, in terms of its effectiveness, if all were acting on the same premise. The classroom grade level teachers and counseling staff were the most clear in their definition of bullying, highlighting the repeated nature of bullying versus singular instances of students being rude or unkind to one another.

\subsection{What Types of Bullying and Contexts Are Considered to Be Most Salient?}

The types of bullying present were identified as predominantly social exclusion or name calling, with occurrence of serious physical altercations being very rare. Many saw the type or form of bullying as differing by age and gender, with girls more likely to utilize name calling or use social exclusion, whereas boys were typically described as using rough teasing and sometimes 'rough housing'.

Some teachers suggest the elementary school day is highly structured, which may reduce bullying in those environments; however, there are monitored but less structured time periods throughout the day (e.g., recess, cafeteria, school bus) where bullying is more difficult to identify and prevent. School personnel recalled bullying incidents occurred in the cafeteria, classroom, on the school bus, and in the gymnasium during physical education (PE) class.

Riding the school bus

$\checkmark \quad$ "I think we have a lot of structure in our day, I just wonder what goes on the buses that worries me. When the kids are out of this structure, and how are they treating each other on the bus?" (content area specialist)

$\checkmark$ "I think a lot of times things go unreported just because kids are afraid to say something, or like I said earlier, it's happening on unstructured times on the bus" (instructional faculty)

$\checkmark$ "With boys it's hard to tell—it looks like rough-necking." (staff employee)

$\checkmark \quad$ "Kids ganging up on other kids... girls ganging up; can be the same person for a long time." (staff employee) 
In the cafeteria for lunch

$\checkmark \quad$ "Yeah and in cafeterias, sometimes I hear table things that go on. But I don't have specifics but those times at recess when there's not as much structure, how are they treating each other?" (content area specialist)

$\checkmark$ "Or in lunch, you know, when there's less supervision and the teachers have, you know. And... I just kind of just try to show up and it's a matter that if I catch it, then I can say, you know, I saw you do that or you seemed to be upset, you or what did you say?" (administrator)

$\checkmark$ “On your way to lunch, in the lunch line." (instructional faculty)

$\checkmark$ "He raised his hand and was real good and everything and then, when his table was released to dump their trash he threw milk on the monitor that was taking the trash." (staff employee)

\section{$\underline{\text { Physical education class }}$}

$\checkmark \quad$ "Um, there was, a couple years ago, I had a boy and he had instances with several bullying issues. Um, he was in PE and there was another boy, the way our PE is structured there's 2 classes in there at the same time." (instructional faculty)

\subsection{What Types of Bullying and Contexts Are Considered to Be Most Salient?}

Predisposing and reinforcing factors for bullying were most commonly identified as unstable homes or emotional states, with additional issues being biased adult responses based on family notoriety, as well as friction from student cultural differences. Some employees indicated feeling helpless or not consistently supported in dealing with more challenging scenarios.

$\checkmark$ "Environmental issues at home" (content area specialist)

$\checkmark$ "Um...we've got some...um...children with the emotionally disturbed label...and a couple of these boys are scary how they treat even adults in our school...volunteers are scared of one $4^{\text {th }}$ grade boy." (content area specialist)

$\checkmark \quad$ "I've had some situations where the leadership protected families [who were well known in the community] when I tried to intervene in a classroom situation there were these boys who were acting out and I thought it was inappropriate. (content area specialist)

$\checkmark \quad$ “... a boy from Korea here, his dad speaks really good English and his mom doesn't and so because of his culture coming into $5^{\text {th }}$ grade - there was a girl who would constantly push him out of line. And nobody really noticed it because, first of all, this girl it was kind of unexpected from this girl but she would always like- and so...one day he just lost it". (instructional faculty) 
3.4 How Were Teachers and Staff Prepared to Prevent or Manage Bullying?

The iterative process revealed school personnel established commonly held expectations for student behavior by creating a safe environment for discussion while also advocating no tolerance for bullying. This standard of behavior was believed to contribute to the development of a school-identity of which to be proud. School personnel agreed that the process for intervening in bullying situations includes education about bullying, so children understand the line between acceptable and unacceptable behaviors, and adult personnel are united in a no tolerance for bullying policy and in agreement about addressing incidents of bullying with quick action.

$\checkmark$ "We nip it in the bud" (instructional faculty)

$\checkmark$ "We work really hard to educate them [children] on what it [bullying] is and if they feel threatened or anything like that we can address it and it's not a big issue here...but we nip it in the bud right away and we stay on it 'til it's done." (instructional faculty)

$\checkmark$ "I think that we don't have issues at the school... and if we do, we address them immediately. Zero tolerance is a good way to go." (instructional faculty)

$\checkmark$ "I think the culture of the school for the kids is there's not tolerance." (instructional faculty)

$\checkmark \quad$ "It's not like saying 'we have zero tolerance and it will not be tolerated, it's just stated to them plainly, you know, how would you feel?" (instructional faculty)

Interviews revealed consensus in the protocol for addressing bullying and was described similarly by most participants, including teachers, content area specialists, administrators, and staff, who agreed school-wide anti-bullying had been effective in diminishing the frequency and intensity of bullying present in the school.

The system advocates for the intervening adult to hear both sides of the incident and to talk it through with the children in context. If there is no resolution at that level, or if the staff is uncomfortable, then the children speak with either the guidance counselors or administrators. Teachers across grade levels, instructional staff, and administrators were in agreement that the protocol has been effective in managing situations as they arise.

$\checkmark$ "Usually what we do is try to handle classroom behavior in the classroom first and let the principal know what's going on and then if it continues then we involve the guidance counselors." (instructional faculty)

$\checkmark \quad$ "We just want them (teachers) to take the first crack at trying to handle any situation. But if they want to keep us informed, if they're frustrated, if they've done something they've tried...I mean we're glad to help. Help them brainstorm or help step in and say 'OK, we'll take it.'” (administrator)

$\checkmark$ "Again, we do a really good job of taking care of it and making sure that it doesn't happen and if it does it is just a lot of discussion, we talk a lot about it." (instructional faculty) 
$\checkmark$ "If there were a bullying situation and I'm going to talk to those two students very quickly, get a rundown of what's going on, which is going to be brief and then take them immediately to the counselor because dealing with that is not my forte. I mean I can lend a little bit of advice and say 'hey, this is what we're going to do' and you know and I'll step in and the intervention will be...let's go talk this out to the counselor, who is a little bit more qualified than I am!” (content area specialist)

$\checkmark \quad$ "A teacher I think will try to work it out, if the parties are all in one grade, or one class, they may work it out. Sometimes I've seen teachers hold kids at lunch and say, 'I want to eat with you. Do you want to share something with me?' Sometimes they'll refer to the counselor" (administrator)

\subsection{Actual Experiences of Staff Managing Instances of Bullying}

Within the protocol for addressing bullying, some variations were noted in the descriptive language choices between teachers and staff members, as they recounted the ways in which they addressed bullying incidents with children. These staff typically responded to bullying within the less structured (non-classroom) environments in which they worked.

$\checkmark \quad$ "Well, I just talk to both students who are involved and tell them, you know, that's not nice, it's not, you know, acceptable and they seem to know what you're saying but then after you leave they might start it again you know. And so you try... Well, if I can't get them to listen I will put them in silent lunch...to separate them and... Now if they're real bad they go to the office and they deal with it there. But I think it's very well handled." (staff employee)

$\checkmark$ "Well the first thing if the kids have a problem with anybody um I make the judgment about whether it's just- whether it's sound or not, but the thing is I'll always trying (sic) to talk, I try to talk to one side of it and if it sounds like it's something I'll get both sides of it. Mainly it's talking to them and reminding them that, what usually seems to work is reminding them of the golden rule. 'Would you like to be treated like this?'... if there's some bullying they'll have to- or if I have a problem with a child who is being physical and I turn it over to the supervisor (principal), I know it's gonna be handled." (staff employee)

\subsection{Guidance counselors}

Guidance counselors at the school are integral to the handling of bullying issues. Their input is valued within the bullying intervention protocol, as staff, teachers, and administrators defer to their expertise.

$\checkmark$ "I've seen counselors have little eating circles with people...community circles. Where if there's a hot button item about, you now, inappropriate talk or making fun of somebody because of this, or whatever, they may just bring it up". (administrator)

$\checkmark$ “...generally, at lunch with the counselors...somebody might share, you know." (administrator) 
$\checkmark$ "One thing that $I$ think is very beneficial... and we have a great counseling program, we have lots of teachers that will make a connection with somebody." (administrator)

\section{Discussion: Opportunities for Continued Improvement}

Systematic literature reviews have yielded mixed results in assessing effectiveness of bullying interventions (Bradshaw, 2015; Menesini \& Salmivalli, 2017), with commonly cited reviews from Ttofi and Farrington (2011) and Merrell et al. (2008). Previous findings have suggested that school-wide interventions for bullying and faculty training are important factors for successful program outcomes (Bradshaw, 2015). In this school, the evidence of trainings includes consistency in the way bullying is defined, an awareness of the process for handling instances of bullying, and a commonly held identity as a source of pride. Reviews of effective programs have supported the idea that program success can be correlated with higher degrees of program fidelity among employees (Menesini \& Salmivalli, 2017). Further, positive school identity and belonging has been indicated as a mitigating factor for victimization among middle- and high school students in the short term, with a continuing emphasis on creating consistent climate and normative expectations (Duggins et al., 2016).

The school has worked collectively and effectively to create a positive student environment through identifying bullying behaviors, the predisposing and reinforcing factors for bullying, and developing a reliable response to bullying behaviors. School personnel have been thoughtful in their development of a protocol and universally adopted that protocol for consistency. This protocol follows the recommended 'response to intervention' framework discussed in public health and education recommendations highlighted by Bradshaw (2015). Though, by most measures, the school's approaches have been successful, there are still some opportunities to improve the school climate and inclusivity.

\subsection{Improve Access to Bullying Training for Employees in Non-teaching Roles}

A National Education Association study indicated teaching faculty were more likely to be engaged in anti-bullying policy development, training, and to perceive bullying as a bigger issue than their educational support staff or other education system employees (Bradshaw, Waasdorp, O’Brennan, \& Gulemetova, 2013). However, Bradshaw and colleagues (2013) also indicated all groups were interested in further training. These findings were similar to the context of the present study. While school personnel generally held a similar definition of bullying across their respective positions, some employment positions appeared to have considerably more exposure to anti-bullying training. Guidance counselors, who often provide the training, and grade level classroom teachers had frequent exposure to bullying reduction and prevention strategies. Similar to the evidence provide by Bradshaw et al. (2013), personnel working in less structured environments, and those with non-teaching positions, received less training and had lesser exposure to prevention strategies, even though less structured environments appear to be a likely environment for bullying to occur. Bradshaw et al. (2013) further suggested that educational support staff are often left out of training or provided a clearly delineated role as a part of a school's bullying prevention program. One staff member referred to themselves as an "outsider" to the process "not in on all of the conversations', but seeing the collective staff were working hard to resolve issues: 
"I can see they handle things, you know, very diplomatically, but you know, respectful of the student." (staff employee). These findings suggest support for the continued development of clear and inclusive policies to effectively reduce bullying behavior (Faucher, Cassidy, \& Jackson, 2015). This dearth of exposure for monitors of less structured environments does present an opportunity to further reduce bullying within the school system, as personnel at the school were universally interested in being a part of the solution.

\subsection{Continued Development of Staff and Student Social Emotional Skills}

Bradshaw (2015) also suggested the evidence supports positive school climate as preventive to bullying behavior. Interviews revealed a consistent protocol for responding to bullying was reported by teachers, administrators, and staff who agreed the school-wide anti-bullying protocols seem effective. School personnel agreed that the process for intervening with bullying situations included quick action to "nip it in the bud" (instructional faculty) approach, employing bullying identification, listening skills, and facilitating student conversations for reconciliation. Some staff reflected on the challenge of finding the balance between allowing students to develop skills for self-regulation and emotionally intelligent responses to conflict and their own memories of childhood conflict.

$\checkmark$ "Something that is a concern to me is that I think um the term bullying has been put out there so much that parents have not let their children handle certain things themselves" (staff employee)

$\checkmark \quad$ "I really want them to enjoy coming to school and to me that really takes away from it. I think if you've been a person who was bullied, I wouldn't say I was bullied but I was teased as a kid about my weight and it was hard and I just didn't like it I hated it, I hated going to school...And it was just, that's where my mind was, it wasn't on academics. I think that's why it has to be important" (instructional faculty)

$\checkmark \quad$ "I can remember being picked on and I'm sure each one of you can remember being picked on for something someone said to you at a certain point in your life and you still remember it." (staff employee)

Durlak, Weissberg, Dymnicki, Taylor, and Schellinger (2011) meta-analytic findings have supported inclusion of social-emotional learning and development as a route to improved student attitudes, skills, and positive social behaviors, as well as reduced conduct issues and emotional distress in universal school program interventions. Durlak et al. (2011) reported classroom teachers were most effective in creating change across variables; however, improvements were also seen when staff provided programming, indicating practices can and should be widely implemented into daily educational practices. Bouchard and Smith (2017) proposed the teacher or staff's own social emotional competencies are often omitted from consideration, but play an important role in creating supportive environments. Jones, Bouffard, and Weissbourd (2013) suggested a teacher or staff member's own social emotional competence will impact students via the quality of their relationships, modeling of social emotional skills, and classroom management practices. A continued emphasis on training is warranted among teachers and staff alike to help students develop competencies in social 
emotional learning areas, such as emotions recognition, stress-management, empathy, problem-solving, or decision-making skills, and to provide employees the opportunities to improve their skills by reflecting on how their own childhood experiences may predispose them to expect or respond to situations they encounter.

\subsection{Responses Are Appropriate to Developmental Stage (Age) But Also May Be Influenced by Cultural and Gendered Stereotypes}

Though most classrooms in the United States are co-educational, there is a wide variation in the extent to which school systems or individual classrooms demonstrate gender integration. Many education professionals omit intentional integration activities because they believe it will happen naturally without facilitation. If teaching staff and students alike erroneously assume gender segregation is natural, it permits the continuance, if not encourages the propagation, of gender-based stereotyping of academic skills and interests. The encouragement of that environment may be detrimental in how students think about and treat each other (Fabes, Martin, Hanish, \& DeLay, 2018). Further, adults' gendered expectations of student behavior have been well documented, with boys being reprimanded at a higher rate and girls expected to be more compliant (Spears Brown \& Stone, 2016). Implicit cultural or gendered biases may contribute to how adults view student interactions and how they respond to situations as they arise. A systematic review reported adult expectations of the normalcy of bullying in childhood are likely to influence situational responses and, thereby, student experiences (Harcourt, Jasperse, \& Green, 2014). These findings are supported by additional reviews of bullying literature, which have suggested bullying, or perceptions of bullying, may vary with age and gender (Menesini \& Salmivalli, 2017).

The student body of the present study is a culturally and socioeconomically diverse one, which further compounds the complexity of addressing bullying universally within a school system. Responses to student bullying situations are typically managed on a case-by-case basis. Employees showed an awareness of, and sensitivity to, how students' individual cultures may contribute to the conflict. However, an opportunity that remains is helping employees to consider their own cultural expectations in how they respond and deem behaviors from the students acceptable or unacceptable. Staff employees with less exposure to bullying training, which may include cultural diversity training, may benefit the most from these exposures. For example, an employee may see aggression and/or "rough housing" as more acceptable in boys, but be much more strict enforcing with girls because the aggression is seen through their own lens of acceptability. Adding differing cultures further complicates the scenario when one child sees rough play as normal, the other child may experience it as extreme aggression, and the adult may view it through a personal cultural lens of what is appropriate for that gender. Social role friction can create opportunities for miscommunication and sometimes bullying based on differing expectations of the social contract for "how one should act". Increasing exposure to gender inclusive and culturally informed training for all employees, but especially those in less structured environments, may help to: 1) foster a more consistent response to situations as they arise and 2) foster a greater employee awareness of how their own culture informs their responses to behavior. By increasing exposure to gender inclusive and culturally informed training, the effectiveness 
and consistency of the approaches used to address conflict are further increased.

\subsection{Sensitivity to Personal Differences Should Be Extended to Employee to Employee Interactions}

Employees put a great deal of care in addressing conflict as it arises between students; however, there appeared to be a less deliberate approach to managing conflict between employees. The hierarchical structure and power domains within education may affirm or tacitly permit uncivil behavior between system employees. J. E. Powell, A. L. Powell, and Petrosko (2015) suggested perceptions of organizational climate are predictive of the amount of incivility or bullying reported among public school employees. Several participants' relayed stories of "pretty horrible bullying with the adults" (content area specialist). However, there were mixed opinions as to whether children were aware of inter-employee conflicts, and some participants indicated they kept it separate or hidden from students, while other educators acknowledged "kids see a lot more than we think they see" (instructional faculty). Occasionally, the employee focus was so entirely on compassionately managing and instructing children that adult incivility was overlooked or deemed unimportant to school culture.

Some researchers have suggested that bullying and harassment happen at higher rates in educational settings compared to other parts of industry (Ariza-Montes, Muniz, Leal-Rodriquez, \& Leal Millan, 2016). The meta-analysis conducted by Bowling and Beehr (2006) suggested that workplace environmental antecedents, such as job demands (role ambiguity and role conflict in particular), were more strongly associated with bullying/harassment behavior than individual characteristics. Subsequently, workplace harassment was clearly predictive of negative consequences for employee well-being (Birkeland Nielsen \& Einarsen, 2012; Bowling \& Beehr, 2006). Others take the recommendation a step further by suggesting the route to healthy organizational climates, which reduce workplace bullying, is through prioritizing resources rather than demands (Ariza-Montes et al., 2016).

Employees were also raised in their own socially replicative situations; they may have been raised to be rule compliant or freely expressive (hard and soft individualism) (Kusserow, 2004), as appropriate to their familial and social contexts. Without self-reflection, adults may carry these expectations forward and experience conflict with other employees. The contrast between student culture and employee culture was starkly evident, as shown by the examples presented in Table 1 below. Including employee treatment of each other as a portion of anti-bullying training may reduce the instances of lateral or relational aggression experienced among employees. 
Table 1. Contrasting visions of the campus culture

\begin{tabular}{|c|c|}
\hline Student Culture & Employee Culture \\
\hline $\begin{array}{l}\text { "[The school] has a zero tolerance policy and they } \\
\text { handle bullying very well. There really isn't any. } \\
\text { [The school] is a very caring and loving } \\
\text { environment. The loving part including hugs and } \\
\text { really loving the kids" (content area specialist) }\end{array}$ & $\begin{array}{l}\text { "But the other side is the culture here. The office staff } \\
\text { pretty much, well, at least } 50 \% \text { of the staff are afraid } \\
\text { of them because they are bullies. They are a little } \\
\text { better, but they are bullies." (content area specialist) }\end{array}$ \\
\hline $\begin{array}{l}\text { I think we have a very good climate, I think we have } \\
\text { a supportive staff, um, there's a lot of } \\
\text { communication between teachers, especially on my } \\
\text { team, we talk everyday about students, about what's } \\
\text { going on and do we see any signs or any issues and } \\
\text { then we're really good about communicating that } \\
\text { with our administration and our counselors, so...I } \\
\text { think it's a good set up" (instructional faculty) }\end{array}$ & $\begin{array}{l}\text { "We have a lot of turnaround in the [specific staff] } \\
\text { department, there's a lot of bullying there. Teacher to } \\
\text { teacher-degrading. If there was a tiff between two } \\
\text { teachers [they're] going to go back to [their] friends" } \\
\text { (content area specialist) } \\
\text {----------- } \\
\text { "I can be friendly to you, why can't you be friendly } \\
\text { back to me? Sorry, I don't like that-and that's from } \\
\text { an adult in this building". (content area specialist) }\end{array}$ \\
\hline $\begin{array}{l}\text { Yeah, I think that our [school] way we show a lot of } \\
\text { team work and working together and if there's } \\
\text { issues happening in the class they need to work } \\
\text { together as friends to figure out what 's happening } \\
\text { and to be able to express what's going on and I } \\
\text { think we do a good job of modeling that" } \\
\text { (instructional faculty) }\end{array}$ & $\begin{array}{l}\text { "The [supervisor] missed the boat - listen to both } \\
\text { sides. Decide. Pretty horrible bullying with adults." } \\
\text { (content area specialist) } \\
\text { "Bullying with students is a bottom tier of issues at } \\
\text { school, within the adults it is a top level issue." } \\
\text { (instructional faculty) }\end{array}$ \\
\hline $\begin{array}{l}\text { "I think the atmosphere here is outstanding. I } \\
\text { honestly am, when you look at the um, the broad } \\
\text { spectrum of children here, either socioeconomic or } \\
\text { just plain, you know, race- uh, this is a very } \\
\text { smoothly run school and I don't mean so much what } \\
\text { they're doing but they've created an atmosphere her } \\
\text { for the kids it works pretty doggone well. I've not } \\
\text { seen any major problems that I know of, you know. } \\
\text { Just the usual kid on kid stuff I see"(staff employee) }\end{array}$ & $\begin{array}{l}\text { "One person goes above and beyond with [their] job, } \\
\text { then gets called in to the office all the time for trivial } \\
\text { issues because [supervisor] believes one person over } \\
\text { another" (instructional faculty) }\end{array}$ \\
\hline
\end{tabular}

\subsection{Limitations and Strengths}

Data collection was limited to one rural elementary school in the mid-Atlantic. Within the present school, interviews were conducted within a variety of roles and positions throughout the school. Within the phenomenological approach of this qualitative study, the goal was to understand the experiences of participants within the particular setting. Although the findings are context-specific, the characteristics of the individuals, situations, and organization are not 
uncommon within the domain of public elementary schools. The use of participants of varied roles within the school highlights the importance of buy-in across all personnel. Furthermore, what began as an exploration of childhood bullying revealed a complex web of adult incivility. This surprising turn has suggested widening the focus on bullying prevention to include instruction on incivility among adults in school settings. Incivility, in this study, occurred within and between adult groups. More specifically, it can be argued that bullying between adult groups, such as instructional faculty to staff employees or vice-versa, is perceived as "bullying," because of differential power among adult positions in an elementary school setting, while the incidents within like-groups are perceived to be peer relational aggression.

\section{Conclusion}

Examples of successful school-wide intervention programs, especially where noting continued areas of improvement, are helpful in establishing replicable patterns for addressing bullying within the elementary school context. However, there is still opportunity for improvement in the provision of anti-bullying training for divergent school groups, as well as in the provision of civility training among the adult employees as a vital contributor to the broader campus culture. Future studies are recommended to expand existing bullying prevention programs for school personnel, particularly for staff employees who engage with children in settings known to harbor bullying incidents. Additional study is also warranted to increase awareness of relational aggression among adults in school settings to determine the impact on job satisfaction, which may contribute to adequately detecting and managing bullying behaviors among children.

\section{References}

Ariza-Montes, A., Muniz, N. M., Leal-Rodriquez, A. L., \& Leal-Millan, A. G. (2016). Workplace bullying among teachers: An analysis from the Job Demands-Resources (JD-R) Model perspective. Journal of Occupational and Environmental Medicine, 58(8), 818-827. https://doi.org/10.1097/JOM.0000000000000804

Barclay, L. J., \& Aquino, K. (2011). Workplace aggression and violence. In S. Zedeck, S. Zedeck (Eds.), APA handbook of industrial and organizational psychology. Maintaining, expanding, and contracting the organization (Vol. 3, pp. 615-640). Washington, DC, US: American Psychological Association. https://doi.org/10.1037/12171-017

Birkeland Nielsen, M., \& Einarsen, S. (2012). Outcomes of exposure to workplace bullying: A meta-analytic review. Work \& Stress, 26(4), 309-332. https://doi.org/10.1080/02678373. 2012.734709

Blair, R. J. (2013). Psychopathy: Cognitive and neural dysfunction. Dialogues in Clinical Neuroscience, 15(2), 181-190.

Bouchard, K. L., \& Smith, J. D. (2017). Teacher-student relationship quality and children's bullying experiences with peers: Reflecting on the mesosystem. The Educational Forum, 81(1), 108-125. https://doi.org/10.1080/00131725.2016.1243182

Bowling, N. A., \& Beehr, T. A. (2006). Workplace harassment from the victim's perspective: 
A theoretical model meta-analysis. Journal of Applied Psychology, 91(5), 998-1012. https://doi.org/10.1037/0021-9010.91.5.998

Bradshaw, C. P. (2015). Translating research to practice in bullying prevention. American Psychologist, 70(4), 322-332. https://doi.org/10.1037/a0039114

Bradshaw, C. P., Waasdorp, T. E., O’Brennan, L. M., \& Gulemetova, M. (2013). Teachers' and education support professionals' perspectives on bullying and prevention: Findings from a National Education Association study. School Psychology Review, 42(3), 280-297.

Cornell, D. G., \& Mayer, M. J. (2010). Why do school order and safety matter? Educational Researcher, 39(1), 7-15. https://doi.org/10.3102/0013189X09357616

Dishion, T. J., \& Tipsord, J. M. (2011). Peer contagion in child and adolescent social and emotional development. Annual Review of Psychology, 62, 189-214. https://doi.org/10.1146/ annurev.psych.093008.100412

Duggins, S. D., Kuperminc, G. P., Henrich, C. C., Smalls-Glover, C., \& Perilla, J. L. (2016). Aggression among adolescent victims of school bullying: Protective roles of family and school connectedness. Psychology of Violence, 6(2), 205-212. https://doi.org/10.1037/ a0039439

Durlak, J. A., Weissberg, R. P., Dymnicki, A. B., Taylor, R. D., \& Schellinger, K. B. (2011). The impact of enhancing students' social and emotional learning: A meta-analysis of school based universal interventions. Child Development, 82(1), 405-432. https://doi.org/10.1111/ j.1467-8624.2010.01564.x

Fabes, R. A., Martin, C. L., Hanish, L. D., \& Delay, D. (2018). Gender integration in coeducational classrooms: Advancing educational research and practice. School Psychology Quarterly, 33(2), 182-190. https://doi.org/10.1037/spq0000266182

Fandrem, H., Strohmeier, D., \& Roland, E. (2009). Bullying and victimization among native and immigrant adolescents in Norway: The role of proactive and reactive aggressiveness. Journal of Early Adolescence, 29(6), 828-923. https://doi.org/10.1177/0272431609332935

Faucher, C., Cassidy, W., \& Jackson, M. (2015). From the sandbox to the inbox: Comparing the acts, impacts, and solutions of bullying in k-12, higher education, and the workplace. Journal of Education and Training Studies, 3(6), 111-125. https://doi.org/10.11114/jets.v3i6.1033

Fink, E., Begeer, S., Peterson, C. C., Slaughter, V., \& de Rosnay, M. (2015). Friendlessness and theory of mind: A prospective longitudinal study. British Journal of Developmental Psychology, 33, 1-17. https://doi.org/10.1111/bjdp.12060

Galanaki, E. P., Polychronopoulou, S. A., \& Babalis, T. K. (2008). Loneliness and social dissatisfaction among behaviourally at-risk children. School Psychology International, 29, 214-229. https://doi.org/10.1177/0143034308090061

Harcourt, S., Jasperse, M., \& Green, V. A. (2014). "We were sad and we were angry": A systematic review of parents' perspectives on bullying. Child \& Youth Care Forum, 43(3), 
373-391. https://doi.org/10.1007/s10566-014-9243-4

Hollis, L. (2012). Bully in the ivory tower: How aggression and incivility erode American higher education. Patricia Berkley LLC Publishing.

Jobe-Shields, L., Cohen, R., \& Parra, G. R. (2011). Patterns of change in children's loneliness: Trajectories from third through fifth grades. Merrill-Palmer Quarterly, 57(1), 25-47.

Jones, S. M., Bouffard, S. M., \& Weissbourd, R. (2013). Educators' social emotional skills vital to learning. Phi Delta Kappan, 94(8), 62-65. https://doi.org/10.1177/003172171309 400815

Kanetsuna, T., Smith, P. K., \& Morita, Y. (2006). Coping with bullying at school: Children's recommended strategies and attitudes to school-based interventions in England and Japan. Aggressive Behavior, 32(6), 570-580. https://doi.org/10.1002/ab.20156

Kusserow, A. (2004). American individualisms: Child rearing and social class in three neighborhoods (culture, mind, and society). New York, NY: Palgrave MacMillan. https://doi.org/10.1057/9781403973986

Ladd, G. W., \& Troop-Gordon, W. (2003). The role of chronic peer difficulties in the development of children's psychological adjustment problems. Child Development, 74, 1344-1367. https://doi.org/10.1111/1467-8624.00611

Liu, J., \& Graves, N. (2011). Childhood bullying: A review of constructs, contexts, and nursing implications. Public Health Nursing, 28(6), 556-568. https://doi.org/10.1111/ j.1525-1446.2011.00972.x

Marsh, H. W., Nagengast, B., Morin, A. J. S., Parada, R. H., Craven, R. G., \& Hamilton, L. R. (2011). Construct validity of the multidimensional structure of bullying and victimization: An application of exploratory structural equation modeling. Journal of Educational Psychology, 103(3), 701-732. https://doi.org/10.1037/a0024122

Menesini, E., \& Salmivalli, C. (2017). Bullying in schools: The state of knowledge and effective interventions. Psychology, Health, \& Medicine, 22(S1), 240-253. https://doi.org/ 10.1080/13548506.2017.1279740

Merrell, K. W., Gueldner, B. A., Ross, S. W., \& Isava, D. M. (2008). How effective are school bullying intervention programs? A meta-analysis of intervention research. School Psychology Quarterly, 23, 26-42. https://doi.org/10.1037/1045-3830.23.1.26

Norris, T. L. (2010). Adolescent academic achievement, bullying behavior, and the frequency of Internet use (Doctoral dissertation, Kent State University). Retrieved from https://etd.ohiolink.edu

Nuance Dragon NaturallySpeaking, Version 13 [Computer software]. Burlington, MA: Nuance.

O'Connell, P. J., Calvert, E., \& Watson, D. (2007). Bullying in the workplace: Survey reports, 2007. Report to the Department of Enterprise, Trade and Employment. Retrieved from 
https://www.esri.ie/pubs/BKMNEXT094.pdf

Olweus, D. (1994). Bullying at School: Basic Facts and Effects of a School Based Intervention Program. Journal of Child Psychology \& Psychiatry, 35(7), 1171-1190. https://doi.org/10.1111/j.1469-7610.1994.tb01229.x

Peachey, A. A., Wenos, J. Z., \& Baller, S. L. (2017). Trait emotional intelligence related to bullying in elementary school children and to victimization in boys. The Occupational Therapy Journal of Research, 37(4), 178-187. https://doi.org/10.1177/1539449217715859

Powell, J. E., Powell, A. L., \& Petrosko, J. M. (2015). School climate as a predictor of incivility and bullying among public school employees: A multilevel analysis. Journal of School Violence, 14(2), 217-244. https://doi.org/10.1080/15388220.2014.906917

Smart, J. (2012). Disability across the developmental life span. New York, NY: Springer Publishing Co.

Spears Brown, C., \& Stone, E. A. (2016). Chapter four: Gender stereotypes and discrimination; How sexism impacts child development. In S. S. Horn, M. D. Ruck, \& L. S. Liben (Eds.), Equity and justice in developmental science: Theoretical and methodological issues (Vol. 50, pp. 105-133). Cambridge, MA: Academic Press. https://doi.org/10.1016/ bs.acdb.2015.11.001

Ttofi, M. M., \& Farrington, D. P. (2011). Effectiveness of school-based programs to reduce bullying: A systematic meta-analytic review. Journal of Experimental Criminology, 7, 27-56. https://oi.org/10.1007/ s11292-010-9109-1

Twale, D. J., \& De Luca, B. M. (2008). Faculty incivility: The rise of the academic bully culture and what to do about it. San Francisco, CA: Josey-Bass.

Wright, M., \& Hill, L. H. (2015). Academic incivility among health sciences faculty. Adult Learning, 26(1), 14-20. https://doi.org/10.1177/1045159514558410

\section{Copyright Disclaimer}

Copyright for this article is retained by the author(s), with first publication rights granted to the journal.

This is an open-access article distributed under the terms and conditions of the Creative Commons Attribution license (http://creativecommons.org/licenses/by/3.0/). 